\title{
Alterations of Thalamic Activity in Schizophrenia and in Response to Antipsychotic Drugs Studies in the Legacy of Seymour S. Kety
}

\author{
Bruce M. Cohen, M.D., Ph.D., and Deborah Yurgelun-Todd, Ph.D.
}

Nature has protected the brain, not only against gravitational and traumatic stresses, but also against the prying eyes and hands of scientists.

Seymour S. Kety, 1979

Seymour Kety became interested in the brain as a young man in high school, and like many before him became determined to gather data on how the human brain worked. Past successes had been few, but as with most things he did, Kety proved more resourceful and clever than his predecessors.

He first set himself the task of understanding human cerebral circulation. Two past attempts had tried to measure cerebral circulation by arteriovenous oxygen difference across the brain. Kety realized that this difference, "being a function of both blood flow and oxygen consumption, was not a valid measure of either alone" (Kety 1979). He would proceed to disentangle them.

His solution was based on the Fick equation (see Figure 1), which itself was derived from the fact that the change in the concentration of a substance in a tissue or organ would be equal to the difference in the substance in entering (arterial) and exiting (venous) blood multiplied by blood flow and duration of flow. The Fick equation required that the organ release or absorb the substance in question at a constant rate. Kety knew that there was no endogenously occurring measurable substance that fulfilled these criteria for the brain. Instead, he and his senior colleague, Carl Schmidt, substituted

From the McLean Hospital, Belmont, Massachusetts and Harvard Medical School, Boston, Massachusetts.

Address correspondence to: Dr. B.M. Cohen, McLean Hospital, 115 Mill Street, Belmont, MA 02487.

Received April 23, 2001; accepted April 28, 2001. an exogenously administered inert gas, nitrous oxide (Kety and Schmidt 1945). The arteriovenous difference in concentration of nitrous oxide would not be a constant, and Kety substituted the integral of the difference for the constant difference of the Fick equation (Kety and Schmidt 1947). Lastly, he could not measure the concentration of nitrous oxide in brain directly. Instead, he reasoned that the ratio of brain to blood nitrous oxide would reach a steady state over time, and that the brain concentration of gas could be estimated from the venous concentration of gas times the solubility constant of nitrous oxide in brain versus blood (Kety 1950). This solubility constant, too, he derived from original experimentation (Kety et al. 1948a).

The Kety-Schmidt equation (see Figure 1) proved to be not just ingenious, but accurate in estimating cerebral blood flow. Knowing cerebral blood flow, Kety could calculate cerebral oxygen consumption from measuring the anteriovenous differences in oxygen levels. Kety, himself, used the techniques he developed to study a wide range of disorders and conditions, examples of which are listed in Table 1. Some of his findings were unexpected, all of them were interesting. For example, he showed that global cerebral oxygen consumption paralleled depth of anaesthesia or coma (Wechsler et al. 1951). Also, contrary to expectations that brain activity would be reduced during normal sleep, he found no reduction in oxygen consumption, presaging the nowcommon knowledge that the brain is quite active during sleep (Mangold et al. 1955).

With his technique, Kety took his first step beyond brain physiology and into the study of psychiatric disorders, by examining cerebral blood flow and oxygen consumption in patients with schizophrenia. He found 


\begin{tabular}{|c|c|}
\hline \multicolumn{2}{|c|}{ Calculating Blood Flow } \\
\hline Fick Equation: & Kety-Schmidt Equation \\
\hline $\mathrm{PE}-$ & $\mathrm{CBF}=-\mathrm{V}_{\mathrm{u}} \cdot \mathrm{S}$ \\
\hline$B F=\overline{(A-V) t}$ & $\int_{0}^{\mathrm{u}}(\mathrm{A}-\mathrm{V}) d t$ \\
\hline
\end{tabular}

Figure 1. In the Fick equation:

BF is blood flow,

$\mathrm{Q}$ is the quantity of reference substance taken up,

$(\mathrm{A}-\mathrm{V})$ is the arteriovenous difference in the reference substance,

$\mathrm{t}$ is the time over which uptake is measured.

In the Kety-Schmidt equation:

CBF is cerebral blood flow,

$\mathrm{V}_{\mathrm{u}}$ is the venous concentration of the reference substance at the end of measurement,

$\mathrm{S}$ is the brain to blood partition coefficient or solubility constant of the reference substance,

$\int_{0}^{\mathrm{u}}(\mathrm{A}-\mathrm{V}) d t$

is the integral of the arteriovenous difference over the time of measurement ( 0 to $\mathrm{u})$.

no disease-related alterations (Kety et al. 1948b). As his method measured global change, the result only suggested that there was no course brain disease in these patients. Kety realized that, as with most disorders of the brain, schizophrenia was characterized by specific symptoms, not global compromise of function, and that abnormalities of brain activity in schizophrenia might only be apparent if techniques were developed to determine regional, not global, activity. He set out to refine his methods to accomplish that purpose.

Regional brain neuronal activity was known to be strongly correlated with regional blood flow and metabolism. With Lou Sokolof, Kety developed the use of radioactive tracers to measure local blood flow and metabolism. They applied the technique in animals, using autoradiography as a means of detection (Landau et al. 1955). Kety suggested that the same approach would apply to the study of human brain with the design of appropriate tracers and external detectors. From these origins came positron emission tomography (PET) and single photon emission computed tomography (SPECT). The principles also apply to functional magnetic resonance imaging (fMRI), in which the tracer is either an exogenously administered paramagnetic agent or endogenous levels of paramagnetic deoxyhemoglobin, each of which affects the local magnetic field and
Table 1. Cerebral Oxygen Consumption and Mental State

\begin{tabular}{lc}
\hline Condition & $\begin{array}{c}\text { Cerebral Oxygen Consumption } \\
\text { (\% of normal) }\end{array}$ \\
\hline Senile psychosis & 82 \\
Diabetic acidosis & 82 \\
Insulin hypoglycemia & 79 \\
Artificial hypothermia & 67 \\
Surgical anesthesia & 64 \\
Insulin coma & 58 \\
Diabetic coma & 52 \\
Alcoholic coma & 49 \\
Normal sleep & 97 \\
Schizophrenia & 100 \\
LSD psychosis & 101 \\
Mental arithmetic & 102 \\
Anxiety & 118 \\
Epinephrine infusion & 122 \\
\hline
\end{tabular}

Source: Kety (1960).

changes the MR signal in accordance with changes in local blood volume and flow.

The methods first developed by Seymour Kety continue to be the basis of human neuroimaging. The findings presented below were obtained by investigators mentored by Seymour Kety, working in laboratories which are the continuation of those he founded at McLean Hospital. They are presented as further evidence of the power of Kety's approach of studying regional brain activity to elucidate clues as to the abnormalities underlying the symptoms and syndromes of psychiatric illness.

\section{DEFINING REGIONAL CHANGES IN BRAIN ACTIVITY IN SCHIZOPHRENIA AND DURING ITS TREATMENT}

It is not likely that any single lesion or dysfunction of any single site is responsible for the diverse symptoms of schizophrenia. However, Seymour Kety's data suggest that there is no substantial general dysfunction of the brain in schizophrenia either.

Rather, schizophrenia may be associated with abnormalities in a small number of brain regions. Candidate regions have been suggested, including the prefrontal cortex, amygdala, hippocampus, anterior cingulate cortex and thalamus (Stevens 1973; Carlsson and Carlsson 1990; Yurgelun-Todd et al. 1996b; Benes 2000). All of these regions are under study in our laboratories and others. Among these regions, the thalamus seems to be one particularly attractive candidate for abnormal function, given that the symptoms of schizophrenia are a dysregulation and disassociation of the elements of perception, thinking and feeling (Andreasen 1995), and the thalamus is part of the circuit modulating perception, thinking and feeling and the integration of these func- 
tions into conscious experience (Crosson and Hughes 1987; Swerdlow and Koob 1987).

Several direct lines of evidence implicate the thalamus in schizophrenia. Structural studies of the brain have included post mortem analyses and in vivo magnetic resonance imaging (MRI). Post mortem analyses consistently show neuronal reductions in thalamus, particularly mediodorsal thalamus, in schizophrenia (Pakkenberg 1990; Bogerts 1993; Shapiro 1993). MRI studies have not only repeatedly demonstrated reductions of thalamic volume (Andreasen et al. 1994; Buchsbaum et al. 1996), but these reductions have been observed early in illness, during first episode of psychosis (Ettinger et al. 2001), and in children with psychotic disorders (Kumra et al. 2000).

Most functional studies also document abnormalities, measured as altered blood flow (Vita et al. 1995; Lewis et al. 1992) or metabolism (Weisel et al. 1987; Tamminga et al. 1992; Buchsbaum et al. 1996), in thalamus in schizophrenia, with these changes correlated to symptom severity. Moreover, antipsychotic drugs, which ameliorate the symptoms of schizophrenia, have also been shown to produce changes of activity in the thalamus, as documented both in animals and human subjects (see Cohen et al. 1998 for review). These findings are exciting because they identify regions of focal pathology in schizophrenia, as well as provide insight into potential treatment strategies.

Several next steps are logical. Past functional studies in human subjects have been general surveys in which brain activity levels are determined in many regions. Also, most past studies have been oriented to documenting baseline activity of the brain rather than regional changes in activity associated with functional demands. Studies focused on the thalamus, per se, are needed and such studies would be made more valuable by using challenge tasks and drug administration to alter thalamic response. Additional human and animal studies to test the extent to which the therapeutic effects of antipsychotic drugs are mediated at least in part in the thalamus would also be valuable. These should include efforts to see if drug-induced alterations in thalamic activity are constant across various and diverse antipsychotic drugs and specific to these drugs, as well as attempts to determine which cells and circuits are responding to antipsychotic drugs. Initial studies of this kind are described below.

\section{ANIMAL MODEL STUDIES}

There are clear limitations in generalizing from animal models to responses in human brain. Nonetheless, animal studies have provided good clues as to the mechanisms and sites of action of psychotropic drugs. In addition, animal studies allow a much higher degree of resolution than human studies.
For antipsychotic drugs, most past studies in animals have focused on the basal ganglia, to which there is a large dopamine input and where the extrapyramidal effects of antipsychotic drugs are likely mediated. In fact, the degree of antipsychotic drug effects in the basal ganglia in the rat correlate highly with extrapyramidal side effects observed during clinical use (Nguyen et al. 1992; Wan et al. 1995).

Far fewer findings have been reported for other brain areas, including the thalamus. The studies which have been published, most of which use 2 deoxyglucose autoradiography, consistently show altered regional metabolic activity in medial thalamic nuclei (McCulloch et al. 1982; Pizzolato et al. 1984, 1987; Tarazi et al. 1992).

The first studies of antipsychotic drug effects in the thalamus at the cellular level of resolution measured expression of the protein Fos, which is elevated in cells with higher activity (Morgan and Curran 1991). These studies observed antipsychotic drug-induced changes in activity of neurons in the midline thalamic nuclei, including the paraventricular nucleus, the centromedial nucleus, the rhomboid nucleus and the nucleus reuniens (Deutch et al. 1995; Cohen and Wan 1996; and see Figure 2). This effect of neuroleptic antipsychotic drugs was observed across a wide range of agents, including the pure dopamine D2 antagonist, raclopride; the typical neuroleptic, haloperidol; the mixed monoamine antagonists, chlorpromazine and thioridazine; the dopamine D2 and serotonin SHT2 antagonists risperidone and olanzapine; and the atypical antipsychotic, clozapine (Cohen et al. 1998; Cohen et al. unpublished observations).

Preliminary evidence shows that the cells responding appear to be Dynorphin containing gabaergic neurons (Ma et al. 2000; and see Figure 3). The actions of

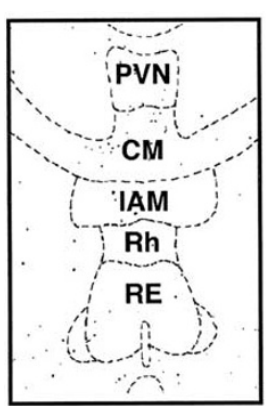

Vehicle

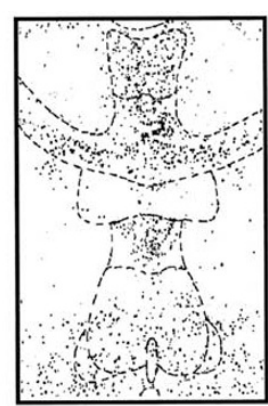

Haloperidol

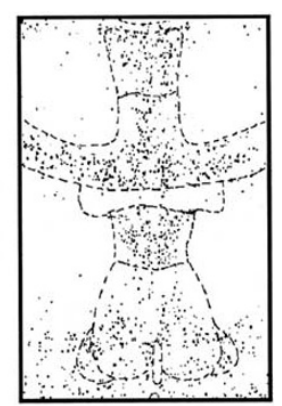

Clozapine
Figure 2. Activation of midline thalamic nuclei by antipsychotic drugs. Computer-generated camera lucida drawings of cells expressing Fos-like immunoreactivity in midline thalamic nuclei, produced from coronal sections at bregma 2.12, from Sprague Dawley rats treated with haloperidol $1 \mathrm{mg} / \mathrm{kg}$ IP, clozapine $20 \mathrm{mg} / \mathrm{kg}$ IP or vehicle. Fos, the protein product of the immediate early gene cfos, identifies activated cells. PVN paraventricular nucleus, CM central medial nucleus, IAM interanteromedial nucleus, $\mathrm{Rh}$ rhomboid nucleus, $\mathrm{RE}$ nucleus reuniens. 


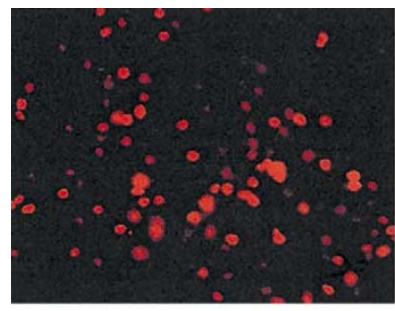

Fos



Dynorphin

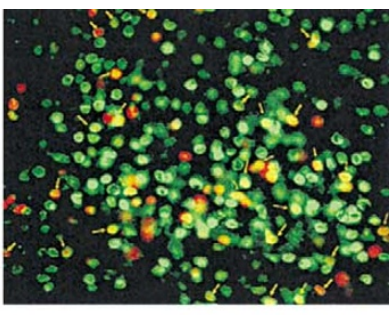

Dynorphin + Fos

Figure 3. In a procedure as described in Figure 2, tissue obtained from Sprague Dawley rats $2 \mathrm{~h}$ after administration of clozapine, $20 \mathrm{mg} / \mathrm{kg} \mathrm{IP}$, was stained with fluorescently tagged antibodies for Fos, a marker of cellular activation, and Dynorphin, a peptide neurotransmitter. The panels show staining for Fos (red), Dynorphin (green) and both markers in the same specimen. Cells expressing both Fos and Dynorphin are yellow from the combined fluorescent emissions. Examples are identified by arrows.

antipsychotic drugs on these neurons may be direct, as there is dopaminergic, noradrenergic and serotonergic innervation of thalamus (Groenwegen 1988; Nieuwenhuys et al. 1988; McCormick 1989; Young and Wilcox 1991; Ma et al. 1991; Huang et al. 1992; Otake and Rug- giero 1995). Alternatively, they may be mediated by drug actions at other sites that are directly or indirectly connected to the thalamus.

Notably, the effects observed in the thalamus are among the few shared by all classes of neuroleptic anti-

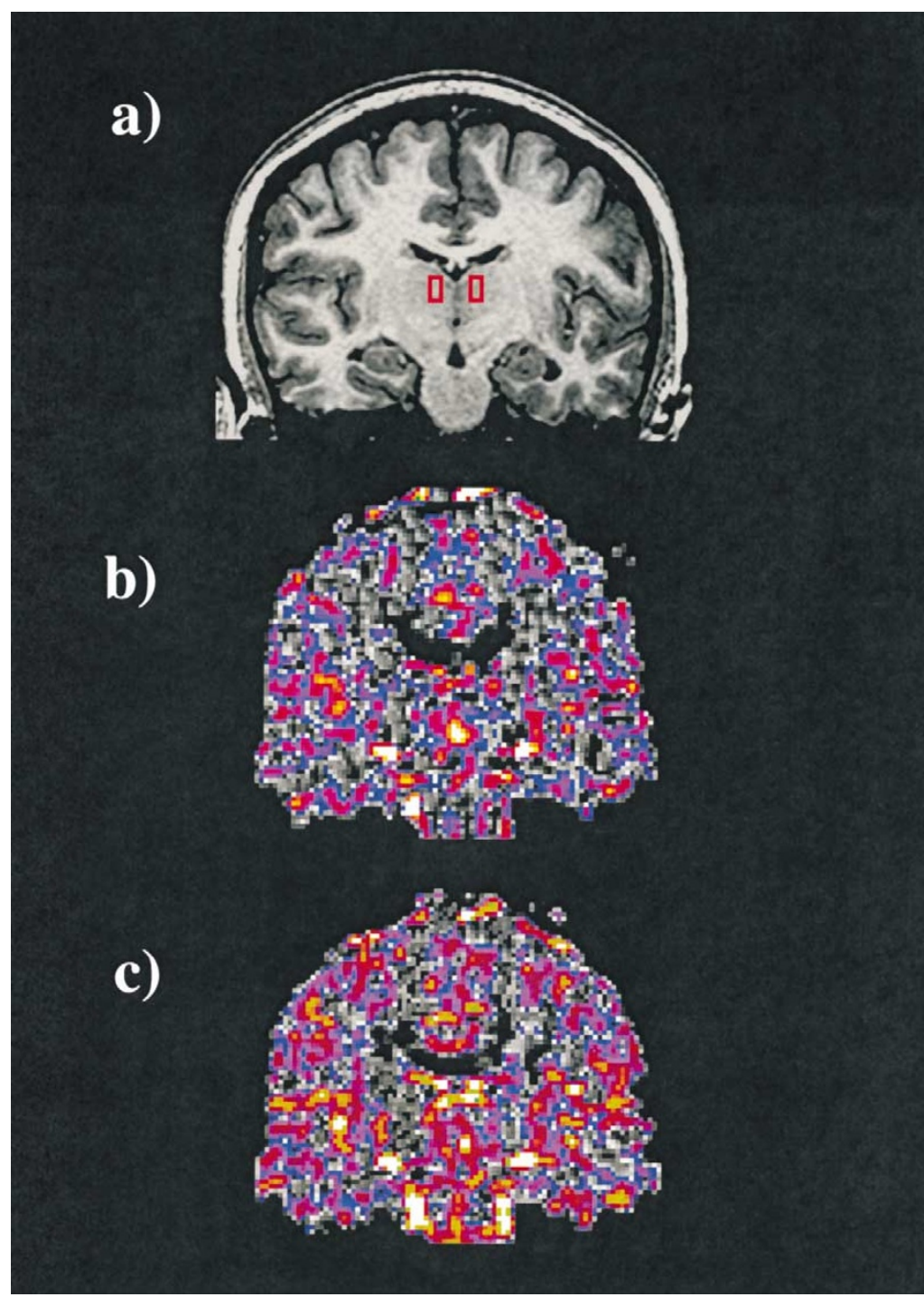

Figure 4. (a) A coronal high-resolution MR image through the thalamus. Red squares indicate the region sampled in measuring changes in cerebral blood volume (CBV). (b) A coronal DSCMRI image illustrating CBV changes after placebo. (c) A coronal DSCMRI image illustrating CBV changes after risperidone. A spinecho planar imaging sequence was used (TR = $1 \mathrm{~s}, \mathrm{TE}=100 \mathrm{~ms}$ ) with a 3-mm skip. All scans were performed on the axial plane. The scans were made following a bolus of gadolinium contrast agent $(0.2 \mathrm{meq} / \mathrm{kg})$ injected over $6 \mathrm{~s}$. Ten functional and $\mathrm{T} 1^{*}$-weighted matched structural images were collected in each subject. Blood volume was calculated using a software program that displays the functional images and provides a tool for drawing multiple regions within each slice. Note increases in $\mathrm{CBV}$ in the thalamic region after risperidone. 
psychotic drugs. Equally important, the effects appear specific to antipsychotic drugs, as they are not shared by anticholinergic sedative or anxiolytic drugs (Cohen et al. unpublished observations). These characteristics suggest that antipsychotic drug-induced changes in activity observed in the thalamus might be associated with the clinical therapeutic effects of antipsychotic drugs.

\section{STUDIES IN HUMAN SUBJECTS}

Thalamic nuclei responding to antipsychotic drugs in animal studies are heavily interconnected to other brain regions suspected of mediating the symptoms of psychosis, including the amygdala, prefrontal cortex, cingulate cortex, hippocampus and nucleus accumbens (Groenwegen 1988; Su and Bentivoglio 1990; Vogt et al. 1993). Comparable thalamic regions in human brain are in mediodorsal thalamus, which includes the mediodorsal thalamic nucleus as well as midline or intralaminar nuclei including the central medial nucleus. These are exactly the regions which show the greatest abnormalities in post mortem (Pakkenberg 1990) and in vivo magnetic resonance structural studies of schizophrenia (Byne et al. 2001).

Functional magnetic resonance imaging provides a powerful approach to explore whether thalamic activity, not just thalamic anatomy, is altered in schizophrenia and whether thalamic activity changes during treatment with antipsychotic drugs. The advantages of fMRI techniques for this purpose include higher spatial and temporal resolution than are available through the alternatives of PET or SPECT (Stoll et al. 2000). In addition, fMRI offers the ability to conduct serial studies safely, allowing dynamic measures of drug effects and activation during cognitive tasks to be obtained (Yurgelun-Todd and Renshaw 1999).

In a protocol comparable to that used in animal studies, the acute regional response of mediodorsal thalamic nuclei to antipsychotic drugs was estimated by cerebral blood volume changes in drug-free, psychiatrically healthy volunteers who took single oral doses of risperidone and placebo. A 3-h time point after dosing was chosen for drug/placebo comparisons based on preliminary studies of the time course of antipsychotic drug effects. Cerebral blood volume (CBV), measured by dynamic susceptibility contrast MRI, increased modestly $(6 \%)$ throughout the brain after risperidone. More prominent increases in CBV (17\%) occurred in mediodorsal thalamus (see Figure 4), as hypothesized. These findings complement the results from animal studies and suggest that thalamic blood volume and activity is altered in human subjects after acute treatment with risperidone.

Abnormality of activation of the thalamus in schizophrenia was tested using blood oxygenation level detection (BOLD) fMRI during performance of a word fluency task which had previously demonstrated signal changes in frontal and temporal regions in these patients (Yurgelun-Todd et al. 1996a). The mediodorsal thalamic nuclei have also been shown to participate during the completion of the word fluency task (Frith 1995). Activation of mediodorsal thalamus showed strikingly little evidence of response in subjects with schizophrenia in contrast to age-matched psychiatrically healthy subjects, even though both groups of subjects performed equally well on the task (see Figure 5). The subjects with schizophrenia were all receiving antipsychotic medication. However, these medications may not explain the difference observed in thalamic activation, since exposure to antipsychotic agents did not alter BOLD response in independent studies of volunteers before and after drug exposure (Cohen et al. unpublished observations).

\section{DISCUSSION}

The studies reported are early attempts to link functional imaging in animal and human subjects, with the purpose of defining the molecular and neuronal circuit alterations that underlie schizophrenia and explain response to treatment. The results obtained are promising, in that drug-related and illness-related changes appear to be documentable at all levels of inquiry. Nonetheless, many issues remain to be addressed about the interpretation of the data.

That the acute administration of the antipsychotic agent risperidone has a general effect on CBV is not surprising, as adrenergic, dopaminergic and serotonergic neurotransmission are all antagonized by risperidone, and all determine vascular tone. The effect is not large as compared with other vasodilating drugs (Levin et al. 1995). Over and above this whole brain effect, a substantial increase in CBV was observed in mediodorsal thalamus. During cognitive tasks or drug challenges, such localized CBV increases can reflect local increases in neuronal activity (Belliveau et al. 1991; Levin et al. 1995). Thus the drug-induced CBV increase in mediodorsal thalamus in human subjects is probably analogous to the Fos protein increase in thalamic neurons in rat studies. Each is a marker of neuronal response.

It is not yet known in rat or human whether changes in thalamic activity are due to direct or indirect effects of antipsychotic drugs. The regions showing activation share reciprocal innervation with prefrontal cortex, amygdala and nucleus accumbens, each of which, in turn, are innervated by dopamine and other monoamine neurons (Groenwegen 1988; Su and Bentivoglio 1990; Vogt et al. 1993; Lavin and Grace 1998). However, the thalamus, too, in human as in rat, shows evidence of dopamine and other monoamine innervation (Nieuwenhuys et al. 1988; Farde et al. 1997). Thus the effects observed may well be direct ones. 


\section{Thalamic Activation in Schizophrenia}
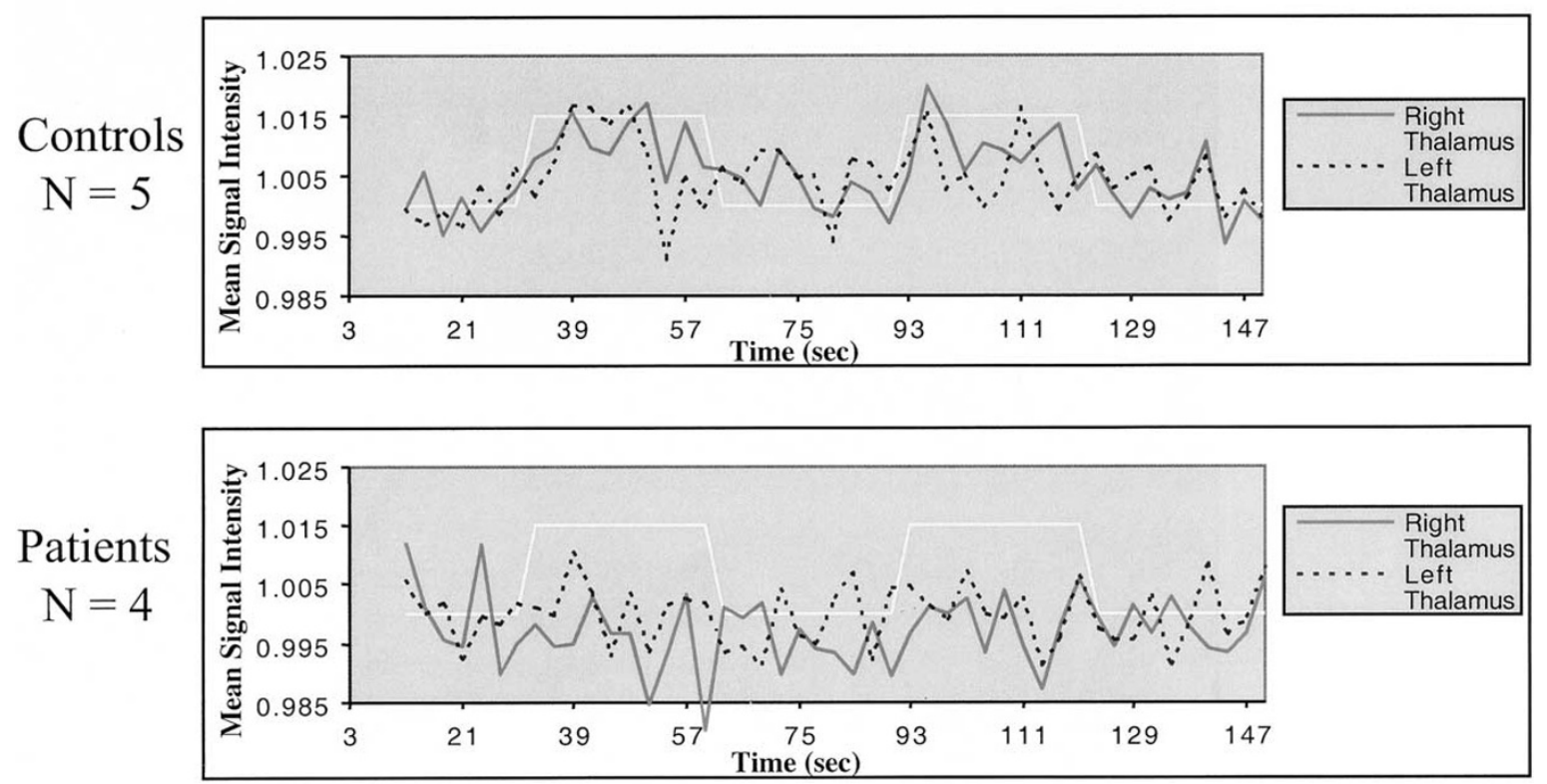

Figure 5. Time-signal intensity plots illustrating the changes in BOLD activity in the medial dorsal thalamus during the verbal fluency task. Data is presented for psychiatrically healthy subjects (top panel) and patients with schizophrenia (bottom panel). Scanning was performed on a 1.5 Tesla scanner using a quadrature head coil. Functional images were collected every $3 \mathrm{~s}$ while the subject was engaged in the cognitive challenge paradigm. The images were acquired using a gradient echo pulse sequence $\left(\mathrm{TE}=40 \mathrm{~ms}\right.$, flip angle $\left.=75^{\circ}\right)$. An image matrix of $64 \times 128$ was used with a $3 \times 3-\mathrm{mm}$ in-plane resolution and a 6-mm slice thickness. Note the clear signal change in healthy subjects, associated with task performance, which is absent in the subjects with schizophrenia.

Results we have observed in animals are consistent with those observed by Deutch et al. (1995), although precisely the same regions were not studied. In human subjects, Bartlett and colleagues surveyed brain response by flurodeoxyglucose (FdG) PET after $5 \mathrm{mg}$ of haloperidol given intramuscularly. Among other findings, they reported decreased glucose metabolism in the thalamus in healthy volunteers (Bartlett et al. 1994) and responders to antipsychotic medication (Bartlett et al. 1998). It is not clear why our study showed an increase in CBV, implying greater activity, and the studies of Bartlett and colleagues showed decreased glucose metabolism. With PET, in contrast to fMRI, it was not possible to isolate a signal from mediodorsal thalamus. Rather, the studies by Bartlett and colleagues included contributions from a much larger region of brain. In addition, both dose and timing may be important determinants of response. We measured effects of a small dose of risperidone at $3 \mathrm{~h}$ after oral dosing, a time when blood and brain levels of drug should be stable or rising. Bartlett and colleagues measured effects of a large dose of haloperidol, but at $12 \mathrm{~h}$ after dosing, at a time when blood and brain levels of drug should be falling. Both findings may well be correct, and the study of effects of other doses and at additional times would be well worthwhile.

The large decrease we observed in apparent activation of the mediodorsal thalamus during a word flu- ency task in subjects with schizophrenia suggests a profound abnormality either related to disease itself or its drug treatment. Crespo-Facorro et al. (1999) observed decreases in regional cerebral blood flow $(\mathrm{rCBF})$ in the thalamus, as measured by ${ }^{15} \mathrm{O} \mathrm{H}_{2} \mathrm{O}$ PET, during recall of word lists in subjects with schizophrenia versus healthy volunteers. The subjects were all drug free. By comparison, Lewis et al. (1992) observed increased rCBF by HmPAO SPECT in thalamus during a word fluency task in medicated subjects with schizophrenia. Neither the PET nor SPECT study surveyed thalamus alone, nor could they focus on mediodorsal thalamus.

Taken as a whole, it appears likely that there are abnormalities of thalamic activation in schizophrenia. However, further investigation will be required with more patients on and off drugs and additional cognitive tasks before the relationship between schizophrenia and abnormal thalamic function can be determined.

\section{CONCLUSION}

Seymour S. Kety was among the most talented of clinical scientists. He was also a gifted thinker concerning the progress of science. He believed that knowledge usually advanced by small steps, based on the contribution of in- 
vestigators of many disciplines, some focused on parts and some on synthesis of the whole of an entity (Kety 1960, 1979). He, himself, made key contributions to several disciplines, including physiology, genetics, and therapeutics.

It was an honor to know Seymour Kety, a privilege to work with him, and a pleasure to have the opportunity to try to build on what he accomplished. We submit our published work and pilot studies as small pieces of the legacy Seymour Kety left through his students.

\section{ACKNOWLEDGMENTS}

The authors acknowledge the contributions of their collaborators Staci Gruber, Marc Kaufman, Nicholas Lange, Jianyi Ma, and Mika Oki and support from the Engelhard Foundation, The National Alliance for Research on Schizophrenia and Affective Disorders, Jeanne and Sanford Robertson, the Stanley Foundation, Virginia and John Taplin, and funding from NIH grant (MH31154). On an historical note, MH31154 is the continuation of Seymour Kety's "Biological Research in Schizophrenia" Program Project Grant, now in its 25th year.

\section{REFERENCES}

Andreasen NC (1995): Symptoms, signs, and diagnosis of schizophrenia. Lancet 346:477-481

Andreasen NC, Arndt S, Swayze V, Cizadlo T, Flaum M, O'Leary D, Ehrhardt JC, Yuh WTC (1994): Thalamic abnormalities in schizophrenia visualized through magnetic resonance image averaging. Science 266:294-298

Bartlett EJ, Brodie JD, Simkowitz P, Dewey SL, Rusinek H, Wolf AP, Fowler JS, Volkow ND, Smith G, Wolkin A, Cancro R (1994): Effects of haloperidol challenge on regional cerebral glucose utilization in normal human subjects. Am J Psychiatry 151:681-686

Bartlett EJ, Brodie JD, Simkowitz P, Schlosser R, Dewey SL, Lindenmayer J-P, Rusinek H, Wolkin A, Cancro R, Schiffer W (1998): Effect of a haloperidol challenge on regional brain metabolism in neuroleptic-responsive and nonresponsive schizophrenic patients. Am J Psychiatry 155:337-343

Belliveau JW, Kennedy D, McKinstry RC, Buchbinder BR, Weisskoff RM, Cohen MS, Vevea JM, Brady TJ, Rosen BR (1991): Functional mapping of the human visual cortex by magnetic resonance imaging. Science 254:716-719

Benes FM (2000): Emerging principles of altered neural circuitry in schizophrenia. In Sedvall G, Terenius L (eds), Schizophrenia: Pathophysiological Mechanisms. New York, Elsevier, pp 236-250

Bogerts B (1993): Recent advances in the neuropathology of schizophrenia. Schizophr Bull 19:431-445

Buchsbaum MS, Someya T, Teng CY, Abel L, Chin S, Najafi A, Haier RJ, Wu J, Bunney WE (1996): PET and MRI of the thalamus in never-medicated patients with schizophrenia. Am J Psychiatry 153:191-199

Byne W, Buchsbaum MS, Kemether E, Hazlett EA, Shinwari A, Mitropoulou V, Siever LJ (2001): Magnetic resonance imaging of the thalamic mediodorsal nucleus and pulv- inar in schizophrenia and schizotypal personality disorder. Arch Gen Psychiatry 58:133-140

Carlsson M, Carlsson A (1990): Schizophrenia: a subcortical neurotransmitter imbalance syndrome? Schizophr Bull 16:425-432

Cohen BM, Wan W (1996): The thalamus as a site of action of antipsychotic drugs. Am J Psychiatry 153:104-106

Cohen BM, Wan W, Froimowitz MP, Ennulat DJ, Cherkerzian S, Konieczna H (1998): Activation of midline thalamic nuclei by antipsychotic drugs. Psychopharmacology 135: 37-43

Crespo-Facorro B, Paradiso S, Andreasen NC, O'Leary DS, Watkins GL, Boles Ponto LL, Hichwa RD (1999): Recalling word lists reveals "cognitive dysmetria" in schizophrenia: a positron emission tomography study. Am J Psychiatry 156:386-392

Crosson B, Hughes CW (1987): Role of the thalamus in language: is it related to schizophrenic throught disorder? Schizophr Bull 13:605-621

Deutch AY, Ongur D, Duman RS (1995): Antipsychotic drugs induce FOS protein in the thalamic paraventricular nucleus: a novel locus of antipsychotic drug action. Neuroscience 66:337-346

Ettinger U, Chitnis XA, Kumari V, Fannon DG, Sumich AL, O'Ceallaigh S, Doku VC, Sharma T (2001): Magnetic resonance imaging of the thalamus in first-episode psychosis. Am J Psychiatry 158:116-118

Farde L, Suhara T, Nyberg S, Karlsson P, Nakashima Y, Hietala J, Halldin C (1997): A PET-study of $\left[{ }^{11} \mathrm{C}\right]$ FLB 457 binding to extrastriatal $\mathrm{D}_{2}$-dopamine receptors in healthy subjects and antipsychotic drug-treated patients. Psychopharmacology 133:396-404

Frith C (1995): Functional imaging and cognitive abnormalities. Lancet 346:615-620

Groenwegen HJ (1988): Organization of the afferent connections of the mediodorsal thalamic nucleus in the rat, related to the mediodorsal-prefrontal topography. Neuroscience 24:379-431

Huang Q, Zhou D, Chase K, Gusella JF, Aronin N, DiFiglia M (1992): Immunohistochemical localization of the $D_{1}$ dopamine receptor in rat brain reveals its axonal transport, pre- and post-synaptic localization, and prevalence in the basal ganglia, limbic system, and thalamic reticular nucleus. Proc Natl Acad Sci USA 89:11,988-11,992

Kety SS (1979): The metamorphosis of a psychobiologist. Ann Rev Neurosci 2:1-15

Kety SS (1960): A biologist examines the mind and behavior. Science 132:1861-1870

Kety SS (1950): Blood flow and metabolism of the human brain in health and disease. Transactions and Studies of the College of Physicians of Philadelphia 18:103-108

Kety SS, Harmel HM, Broomell HT, Rhode CB (1948a): The solubility of nitrous oxide in blood and brain. J Biol Chem 173:487-496

Kety SS, Schmidt CF (1947): The nitrous oxide method for the quantitative determination of cerebral blood flow in man: theory, procedure and normal values. From the Department of Pharmacology, University of Pennsylvania, Philadelphia. 476-483

Kety SS, Schmidt CF (1945): The determination of cerebral blood flow in man by the use of nitrous oxide in low concentrations. Am J Physiology 143:53-66 
Kety SS, Woodford RB, Harmel MH, Freyhan FA, Appel KE, Schmidt CF (1948b): Cerebral blood flow and metabolism in schizophrenia. The effects of barbiturate semi-narcosis, insulin coma and electroshock. Am J Psychiatry 104:765-770

Kumra S, Giedd JN, Vaituzis AC, Jacobsen LK, McKenna K, Bedwell J, Hamburger S, Nelson JE, Lenane M, Rapoport JL (2000): Childhood-onset psychotic disorders: magnetic resonance imaging of volumetric differences in brain structure. Am J Psychiatry 157:1467-1474

Landau WM, Freygand WH, Rowland LP, Sokoloff L, Kety SS (1955): The local circulation of the living brain: values in the unanesthetized and anesthetized cat. Trans Am Neuro Assoc 80:125-129

Lavin A, Grace AA (1998): Response of the ventral pallidal/ mediodorsal thalamic system to antipsychotic drug administration: involvement of the prefrontal cortex. Neuropsychopharmacology 18:352-363

Levin JM, Kaufman MJ, Ross MH, Mendelson JH, Maas LC, Cohen BM, Renshaw PF (1995): Sequential dynamic susceptibility contrast MR experiments in human brain: residual contrast agent effect, steady state, and hemodynamic pertubation. Magnet Res Med 34:655-663

Lewis SW, Ford RA, Syed GM, Reveley AM, Toone BK (1992): A controlled study of ${ }^{99 \mathrm{~m}} \mathrm{Tc}-\mathrm{HMPAO}$ single-photon emission imaging in chronic schizophrenia. Psychol Med 22:27-35

Mangold R, Sokoloff L, Conner E, Kleinerman J, Therman PG, Kety SS (1955): The effects of sleep and lack of sleep on the cerebral circulation and metabolism of normal young men. J Clin Invest 34:1092-1100

Ma J, Ye Z, Cohen B (2000): Dynorphin-containing neurons responding to neuroleptic antipsychotic drugs in the rat forebrain and thalamus. Society of Neuroscience Annual Meeting 97:7

Ma QP, Yin GF, Ai MK, Han JS (1991): Serotonergic projections from the nucleus raphe dorsalis to the amygdala in the rat. Neurosci Lett 134:21-24

McCulloch J, Savaki HE, Sokoloff L (1982): Distribution of effects of haloperidol on energy metabolism in the rat brain. Brain Res 243:81-90

McCormick DA (1989): Cholinergic and noradrenergic modulation of thalamocortical processing. Trends in Neurosci 12:215-221

Morgan JI, Curran T (1991): Stimulus-transcription coupling in the nervous system: involvement of the inducible proto-oncogenes. Annu Rev Neurosci 14:431-451

Nieuwenhuys R, Voogd J, van Huijzen C (1988): Ascending Reticular Systems. The Human Central Nervous System: A Synopsis and Atlas, 3rd ed. Berlin, SpringerVerlag, pp. 198-220

Nguyen TV, Kosofsky BE, Birnbaum R, Cohen BM, Hyman SE (1992): Differential expression of c-fos and zif 268 in rat striatum after haloperidol, clozapine, and amphetamine. Proc Natl Acad Sci USA 89:4270-4274

Otake K, Ruggiero DA (1995): Monoamines and nitric oxide are employed by afferents engaged in midline thalamic regulation. J Neurosci 14:1891-1911

Pakkenberg B (1990): Pronounced reduction of total neuron number in mediodorsal thalamic nucleus and nucleus accumbens in schizophrenia. Arch Gen Psychiatry 47: 1023-1028

Pizzolato G, Soncrant TT, Rapoport SI (1984): Haloperidol and cerebral metabolism in the conscious rat: relation to pharmacokinetics. J Neurochem 43:724-732
Pizzolato G, Soncrant TT, Larson DM, Rapoport SI (1987): Stimulatory effect of the D2 antagonist sulpiride on glucose utilization in dopaminergic regions of rat brain. J Neurochem 49:631-638

Shapiro RM (1993): Regional neuropathology in schizophrenia: where are we? Where are we going? Schizophr Res 10:187-239

Stevens JR (1973): An anatomy of schizophrenia. Arch Gen Psychiatry 29:177-189

Stoll AL, Renshaw PF, Yurgeun-Todd DA, Cohen BM (2000): Neuroimaging in bipolar disorder: what have we learned? Biol Psychiatry 48:505-517

Su H-S, Bentivoglio M (1990): Thalamic midline cell populations projecting to the nucleus accumbens, amygdala, and hippocampus in the rat. J Comp Neurol 297:582-593

Swerdlow NR, Koob GF (1987): Dopamine, schizophrenia, mania and depression: toward a unified hypothesis of cortico-striatopallido-thalamic function. Behav Brain Sci 10:197-245

Tamminga CA, Thaker GK, Buchanan R, Kirkpatrick B, Alphs LD, Chase TN, Carpenter WT (1992): Limbic system abnormalities identified in schizophrenia using positron emission tomography with fluorodeoxyglucose and neocortical alterations with deficit syndrome. Arch Gen Psychiatry 49:522-530

Tarazi F, Shirakawa O, Tamminga CA (1992): Low dose raclopride spares the extrapyramidal system in rat brain from metabolic effects. Eur J Pharmacol 232:71-77

Vita A, Bressi S, Perani D, Inverizzi G, Giobbio GM, Dicci M, Garbarini M, Sole AD, Fazio F (1995): High-resolution SPECT study of regional cerebral blood flow in drugfree and drug-naïve schizophrenia patients. Am J Psychiatry 152:876-882

Vogt BA, Sikes RW, Vogt LJ (1993): Anterior cingulate cortex and the medial pain system. In Vogt BA, Gabriel M (eds), Neurobiology of Cingulate Cortex and Limbic Thalamus: A Comprehensive Handbook. Boston, Birkhauser, pp 314-344

Wan W, Ennulat DJ, Cohen BM (1995): Acute administration of typical and atypical antipsychotic drugs induces distinctive patterns of Fos expression in the rat forebrain. Brain Res 688:95-104

Wechsler RL, Dripps RD, Kety SS (1951): Blood flow and oxygen consumption of the human brain during anesthesia produced by thiopental. Anesthesiology 12:308-314

Weisel FA, Wik G, Sjogren I, Blomqvist G, Greitz T, StoneElander S (1987): Regional brain glucose metabolism in drug free schizophrenic patients and clinical correlates. Acta Psychiatr Scand 76:628-641

Young KA, Wilcox RE (1991): Characterization of $\mathrm{D}_{2}$ receptors and dopamine levels in the thalamus of the rat. Life Sci 48:1845-1852

Yurgelun-Todd DA, Kinney DK, Sherwood AR, Renshaw PF (1996b): Magnetic resonance studies of schizophrenia. Sem Clin Neuropsychiat 1:4-19

Yurgelun-Todd DA, Waternauz CM, Cohen BM, Gruber SA, English CD, Renshaw PF (1996a): Functional magnetic resonance imaging of schizophrenics and controls during word production. Am J Psychiatry 153:200-205

Yurgelun-Todd DA, Renshaw PF (1999): Applications of fMRI to research in psychiatry. In Heiserman JE, Drayer BP (eds), Neuroimaging Clinics of North America. Philadelphia, PA, W.B. Saunders, pp 295-309 